\title{
PMLA
}

PUBLICATIONS OF

THE-MODERN-LANGUAGE-ASSOCIATION-OF-AMERICA

Issued Five Times a Year

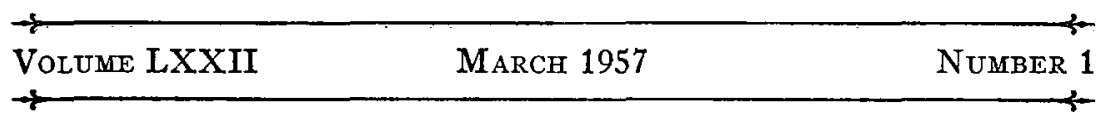

\section{EDITORIAL POLICY OF PMLA}

W

E VENTURE to reaffirm the policy which has guided the selection of articles during the past decade, namely, that $P M L A$ should reflect the most distinguished American scholarship in the modern languages and literatures. It is not a place for beginners to try their wings, unless those wings are used for sure and significant flight; and it is not a place for established scholars to publish their incidental writings, unless those writings compare in excellence and value with those of younger men. As the official Publications of the Modern Language Association of America PMLA should publish to the learned world the most important work of members of the Association.

We affirm, moreover, that the distribution of papers in PMLA should reflect work of distinction actually being done from year to year, regardless of periods or languages. Thus when literary or philological research in a certain field is at a low ebb and research in another is flourishing, we should print articles from the latter. We should not strain for wide coverage in period or language at the cost of publishing articles of indifferent research or undistinguished writing. Members who feel their interests neglected by this policy can always alter the situation by writing, and by encouraging others to write, articles good enough to be published. PMLA should reveal the best American scholarship as it is-not as it was, not as it theoretically should be. Equal representation of fields puts a tax on excellence.

We affirm that $P M L A$ exists to encourage the advancement of literary and linguistic learning on the widest possible front. It welcomes new approaches to literary or linguistic study which are based upon sound scholarship, and it disavows any exclusive preference for conventional methods or for traditional papers on traditional subjects. Explicitly it invites important articles dealing with critical theory, the history of ideas, analytical bibliography, and American (or other) civilization, provided only that these articles have literary relevance. 
While PMLA wishes to introduce to the Association new scholars and new lines of inquiry, it is reluctant to publish minor articles or highly technical studies addressed to specialists in various but limited fields. These are often more suitable for specialist journals. The editors also seek to discourage either brief notes (the staple of several other periodicals) or unduly long papers. $P M L A$ does not review books. The audience for $P M L A$ articles is the total membership. Writers are requested to keep the broad interests of the membership in mind when addressing their papers to them.

Although PMLA is not a journal of belles lettres, and publishes nothing addressed to a wider audience than the Association represents, it insists that articles on whatever subject should be written in a clear and readable style. This criterion should not be construed as an encouragement of florid or expansive writing. Space is at a premium. Economy of words and tightness and clarity of organization are prominent among the standards by which articles will be judged for acceptance. Documentation should be held to a necessary minimum.

Every member of the Association has the privilege, denied to nonmembers, of submitting papers for publication in $P M L A$. Every paper submitted will be read by at least one consultant with special competence in the field of study. Papers in any way recommended will also be read by at least one member of the Editorial Committee. Rejected papers will be returned, if possible, within about two months. Acceptance of papers may be conditional upon their revision in the light of specific criticisms. Attempt is made to publish papers within nine months of acceptance. Members are asked to consider that the services of consultant readers are made possible by the unpaid labors of many distinguished men and women who generously contribute their scant leisure to the advancement of scholarship in humane letters in America.

Manuscripts must be prepared in conformity with the Mla Style Sheet published in the April $1951 P M L A$, which is on sale as a pamphlet in the MLA offices. Authors are advised to read also the advice of R. B. McKerrow and H. M. Silver on the publication of research, published in the 1950 issue.

Manuscripts should be addressed to the Editor of PMLA, 6 Washington Square North, New York 3, N. Y. Stamps need not be enclosed. Carbon copies are not needed, but should be made and retained by authors, since manuscripts sometimes get lost.

The EDITOR

(for the Editorial Committee) 